\title{
"Histórias de vida" em formação docente no âmbito de um subprojeto do PIBID-UFES: narrativas de duas licenciadas em Química acerca das suas vivências formativas na Escola Básica
}

"Life history" on teacher training PIBID-UFES: narrative life history of two chemistry pre-service teachers about their formative experiences on school

Hedylady Santiago Machado

Caian Cremasco Receputi

Marcos Vogel

\begin{abstract}
Resumo: Esta pesquisa é parte dos resultados da Dissertação de Mestrado de um dos autores, que se encontra em processo de finalização, cujo o tema é a formação inicial de professores de Química no âmbito de um subprojeto do PIBID da UFES, Campus Alegre. Esta comunicação teve como objetivo apresentar os resultados do estudo sobre os aspectos das vivências formativas no contexto da Escola Básica de duas licenciadas em Química, bolsistas de Iniciação à Docência. Para tanto, foram realizadas Entrevistas Narrativas com as licenciadas, tendo como aporte teóricometodológico na pesquisa a Abordagem Biográfica e de Histórias de Vida em formação, em que é o participante que evidencia, por meio da narrativa, o que considera mais importante durante seu processo formativo atribuindo significados ao que foi vivenciado. A análise das entrevistas foi inspirada nas proposições da análise de conteúdo de Bardin. Os resultados foram agrupados em três subeixos temáticos: reconhecimento do espaço escolar e acompanhamento das turmas, desenvolvimento de métodos de ensino com os alunos das escolas parceiras, relação com alunos e profissionais da Educação Básica. Estes subeixos evidenciam aspectos relacionados a essas vivências formativas do subprojeto, reflexões das licenciadas sobre a formação inicial docente na Educação Básica, que, em síntese, indicam que participar do subprojeto PIBID-QUÍMICA-UFES-ALEGRE contribui para a formação inicial docente em Química no espaço formativo do ambiente escolar.
\end{abstract}

Palavras-Chave: Formação inicial docente; Histórias de vida; Entrevista Narrativa; PIBID-Química.

Abstract: This paper presents part of a Master Thesis' results in progress, which theme concerns initial chemistry teacher training PIBID-UFES, located in the city of Alegre. This communication presents the results of a study on school formative experiences of two chemistry pre-service teachers scholarships. Narrative interviews were carried out with two PIBID scholarships students, grounded on theoretical and methodological biographical approach, which goal is to get the participants reconstruction of their experiences related to the topic under study. The analysis of the interviews, was inspired by Bardin content analysis propositions. The results were classified into three thematic sub-axes: acknowledgment of school space and monitoring classes activities, development teaching methods with students school partner, relationship with Basic Education students and professionals. It was identified experiences of chemistry pre-service teachers about their formative experiences on school, through the development of the activities on PIBID. Was conclude that the 
PIBID-QUÍMICA-UFES-ALEGRE experience has contributed to chemistry pre-service teachers development.

Keywords: Initial teacher training; Life History; Narrative Interview; PIBID-Chemistry subproject.

\section{Formação de Professores de Química}

Os cursos de graduação em licenciatura possuem o objetivo de formar profissionais docentes para atuarem na Educação Básica (GATTI, 2010). A publicação da Lei de Diretrizes e Bases da Educação Nacional (LDB) No 9.394, em 23 de dezembro de 1996 (BRASIL, 1996), conforme disposto em seu Art. 62, foi um importante passo para propor essa formação profissional docente nas instituições formadoras e nos cursos de formação de professores, no sentido de determinar uma formação em nível superior para atuação na Educação Básica. Todavia, mesmo após a publicação desta lei, percebia-se marcas da legislação anterior na estrutura curricular dos cursos de formação de professores (GATTI; BARRETTO, 2009).

Esse esquema de formação docente, estruturado nos cursos de formação de professores no início do século $X X$, fora denominado de $3+1$ (SCHEIBE, 2008), pois "[...] a partir da formação de bacharéis durante três anos, [acrescentava-se] um ano de formação com disciplinas da área da educação para a obtenção da licenciatura, esta dirigida a formação de docentes para o ensino secundário" (GATTI; BARRETTO, 2009, p. 37). Entretanto, este modelo formativo apresentava forte desintegração entre essas duas áreas de conhecimento, contribuindo claramente para a "[...] secundarização da área pedagógica no ensino superior, no qual o bacharelado se constituiu como área privilegiada" (SCHEIBE, 2008, p. 47-48).

Essa discussão fomenta reflexões sobre as práticas de formação que ainda se efetivam em muitos cursos de Licenciatura em Química atualmente, e, consequentemente sobre o ensino de Química nas instituições formadoras, pois é notório que "[...] na maioria dos cursos, [a formação do professor de Química] ainda se baseia em uma formação pautada pelo conteúdo e forma do bacharelado (VOGEL et al., 2018, p. 125). 
Silva e Oliveira (2009) contribuem para essa discussão ao afirmarem que nesses cursos o que ganha relevância é a formação do químico e não do professor de Química, garantindo que o egresso possua grande embasamento teórico e prático químico. Além disso, a articulação entre os conhecimentos específico e pedagógico parece não ser de responsabilidade dos docentes das disciplinas de conteúdo específico. De acordo com Schnetzler (2000), nessas disciplinas, pouca ou nenhuma consideração tem sido direcionada sobre o que, como e porque ensinar Química, Física ou Biologia para os alunos na Escola Básica.

Por outro lado, essa dicotomia teoria-prática igualmente persiste nas disciplinas pedagógicas, pois exceto as disciplinas de Didática e de Práticas de Ensino, as demais caracterizam-se pela dissociação entre o tratamento de teorias e modelos pedagógicos e o conteúdo científico que os futuros professores necessitarão lecionar (SCHNETZLER, 2000). Além disso, em algumas instituições esses professores formadores são docentes que não possuem formação em Química dificultando, desta forma, a aproximação entre essas áreas de conhecimentos químicos e pedagógicos (SILVA; OLIVEIRA, 2009).

Nas últimas décadas, o modelo educacional dito $3+1$, vem sendo vigorosamente refutado (ECHEVERRÍA; BENITE; SOARES, 2007). Na área de Ensino de Química, compreende-se que a qualidade dos processos de formação docente em Química perpassa pela melhoria da prática docente, pela reflexão e análise da prática e do confronto com outras práticas docentes (GIMENO; PEREZ, 2000 apud SILVA; SCHNETZLER, 2005). Nessa vertente, encontram-se iniciativas de grupos de pesquisa e de formação docente de Universidades Brasileiras que tem se dedicado a investigar os contextos de formação e buscar caminhos que proporcionem "[...] processos que articulem os conhecimentos específico (da Química) e educacionais, tendo em vista a reflexão crítica necessária à constituição do ser professor e ao exercício da docência" (VOGEL et al., 2018, p. 126).

Neste contexto, entra em cena o Programa Institucional de Bolsas de Iniciação à Docência (PIBID) visando contribuir para a reflexão dos dilemas 
"[...] enfrentados pela formação de professores, desde suas deficiências de formação, até os altos índices de evasão universitária e a necessidade permanente de novos profissionais bem formados para a Educação Básica" (VOGEL, 2016, p. 155).

\section{O Programa Institucional de Bolsa de Iniciação à Docência (PIBID)}

O PIBID "[...] é um programa de incentivo e valorização do magistério e de aprimoramento do processo de formação de docentes para a educação básica" (CAPES-DEB, 2014, p. 63), e tem sua origem em uma ação do governo federal, por meio da Portaria Normativa do Ministério da Educação (MEC) $n^{\circ}$ 38, de 12 de dezembro de 2007 (BRASIL, 2007). O programa determina que os alunos das licenciaturas participantes devem exercer atividades didáticas em escolas de Educação Básica, "[...] contribuindo para a integração entre teoria e prática, para a aproximação entre universidades e escolas e para a melhoria da qualidade da educação brasileira [...]" (GATTI et al., 2014, p. 5).

Estudos têm identificado que participar de projetos PIBID contribui no desenvolvimento profissional dos professores do ensino superior das Instituições de Ensino Superior participantes, fomentando nesses profissionais o desenvolvimento de novas compreensões sobre educação, escola e práticas educativas, refletindo tanto na dinâmica do PIBID quanto nos cursos de licenciatura (PEREIRA, RECEPUTI, REZENDE, 2020; SILVA, 2015).

No curso de Licenciatura em Química da Universidade Federal do Espírito Santo, campus de Alegre, as ações do PIBID foram iniciadas no ano de 2010 (VOGEL, 2016).

O subprojeto de área do PIBID-QUÍMICA-UFES-ALEGRE tem como princípio norteador prover ao licenciando, bolsista de iniciação à docência (bolsistas de ID) ${ }^{1}$, a oportunidade de fazer parte da realidade da escola, reforçando os laços entre a Escola Básica e a Universidade, para que o licenciando se forme com base nas experiências de sala de aula. $O$ pressuposto é que este, adentrado no espaço escolar, possa observar de perto

\footnotetext{
${ }^{1}$ Bolsistas de iniciação à docência (bolsistas de ID) são licenciandos regularmente matriculados em cursos de licenciatura e são o foco do PIBID (CAPES-DEB, 2014).
} 
o trabalho do professor supervisor e junto com ele potencializar ações formativas docentes e de intervenção na realidade da escola parceira.

No processo, o bolsista de iniciação à docência é orientado a discutir em grupo como os diferentes formatos de estratégias de ensino podem ser levados para a escola e como afetam o processo de ensino e aprendizagem dos alunos.

A partir disso, desde o ano de 2012 o subprojeto também tem adotado práticas de formação inicial docente, por meio da escrita relatos reflexivos, ou narrativas autobiográficas, pelos bolsistas de ID. Fundamentadas no aporte teórico de Josso (2007), essas narrativas evidenciam as histórias de vida em formação. A história de vida é "[...] uma mediação do conhecimento em si em sua existencialidade, que oferece à reflexão de seu autor oportunidades de tomada de consciência sobre diferentes registros de expressão e de representações de si, assim como, sobre as dinâmicas que orientam sua formação" (JOSSO, 2007, p. 419).

No que diz respeito à pesquisa-formação de professores, as narrativas constituem duas vertentes de trabalho no campo biográfico: por um lado, a pesquisa que usa a narrativa no ensino e na formação, e, por outro lado, a investigação da narrativa (CUNHA, 1997). Neste sentido, o subprojeto do PIBID-QUÍMICA-UFES-ALEGRE fundamentou-se na primeira vertente, por outro lado a pesquisa que está sendo desenvolvida, fundamenta-se na segunda vertente.

Portanto, a questão que norteia a pesquisa de mestrado se refere a quais os aspectos das vivências do subprojeto PIBID-QUÍMICA-UFESALEGRE, narrados pelas(os) licenciadas(os) em Química, no processo formativo inicial docente? O objetivo desta comunicação é apresentar os resultados da análise das vivências formativas no contexto da Escola Básica de duas licenciadas em Química, participantes do referido subprojeto.

\section{Percurso Metodológico}

Para responder a questão da pesquisa e alcançar o objetivo proposto, optou-se por utilizar os fundamentos da abordagem qualitativa de pesquisa, 
cujos princípios podem ser sintetizados em cinco características de acordo com Lüdke e André (2014): i) a coleta de informações ocorreu diretamente com os sujeitos da pesquisa por meio da realização de entrevistas narrativas, mas o contato direto da pesquisadora com o ambiente investigado ocorreu durante sua participação no referido subprojeto de formação, entre os anos de 2014 até meados de 2016; ii) a coleta de informações teve como resultado os dados descritivos, isto é, as entrevistas narrativas que foram transcritas para um programa de edição de textos; iii) houve a preocupação com o processo formativo inicial docente dos participantes, desde o momento da proposição da questão problema até a investigação dos aspectos desse processo; vi) o foco de investigação das narrativas foi o que os participantes evidenciaram como mais importante durante seu processo formativo no subprojeto e os significados que atribuíram ao que foi vivenciado nesse espaço formativo; v) e por fim, a análise das informações obtidas seguiu um processo indutivo.

A partir disso, constituiu-se como percurso metodológico para esta pesquisa as concepções teórico-metodológicas da abordagem Biográfica e de História de Vida, articulando-se com o contexto das vivências das licenciadas no subprojeto PIBID-QUÍMICA-UFES-ALEGRE, que passaram pelo filtro interpretativo dos pesquisadores (MINAYO; DESLANDES; GOMES, 2009).

\section{Participantes}

Os sujeitos da pesquisa foram duas licenciadas e dois licenciados em Química formados na UFES, Campus de Alegre, e do subprojeto do PIBIDQUÍMICA-UFES-ALEGRE entre os anos de 2013 a 2018, período em que as produções autobiográficas foram trabalhadas no subprojeto como atividade formativa para os bolsistas de ID. Apresentaremos os resultados de parte das entrevistas das duas licenciadas Maria e Núbia. Durante toda a pesquisa foram adotados nomes fictícios para que fosse resguardada a identidades dos participantes. 


\section{Entrevista Narrativa como instrumento de coleta de informações}

A Entrevista Narrativa (EN) fundamentada em Jovchelovitch e Bauer (2002) se constituiu como um potencial instrumento de coleta de informações, pois havia a premissa de que possibilitasse aos participantes uma situação que e os encorajassem e os estimulassem a narrar, relatar, contar algum acontecimento de suas histórias de vida em formação e do contexto formativo, destacando os acontecimentos que considerassem mais importantes em seu processo de formação. O procedimento de Entrevista Narrativa procedeu a partir de cinco fases, sumariadas no Quadro 1:

Quadro 1 - Fases da Entrevista Narrativa

\begin{tabular}{|l|l|}
\hline Fases da EN & Descrição das Fases \\
\hline Preparação & $\begin{array}{l}\text { Momento em que se construiu a estrutura de EN com base } \\
\text { nos objetivos e problemas da pesquisa. }\end{array}$ \\
\hline Iniciação & $\begin{array}{l}\text { Dividida em duas etapas, a primeira refere-se à perguntas } \\
\text { em relação ao perfil dos participantes, e, a segunda etapa, } \\
\text { refere-se ao tópico inicial de narração acerca das histórias } \\
\text { de vida em formação no subprojeto PIBID: "Conte-me } \\
\text { sobre seu processo formativo inicial docente, durante sua } \\
\text { participação no PIBID-QUÍMICA-UFES-ALEGRE (Pode } \\
\text { começar de onde desejar)". }\end{array}$ \\
\hline Narração central & $\begin{array}{l}\text { Narração do participante. Após a narração, para o } \\
\text { incentivar a complementar a história sobre sua trajetória no } \\
\text { subprojeto, perguntou-se: "É tudo que você gostaria de me } \\
\text { contar? Ou haveria ainda alguma coisa que você gostaria } \\
\text { de dizer?". }\end{array}$ \\
\hline Fase de perguntas & $\begin{array}{l}\text { A partir do que foi narrado foram realizadas perguntas } \\
\text { mais específicas, direcionadas aos objetivos e problemas } \\
\text { inicialmente construídos na pesquisa, visando aprofundar } \\
\text { aspectos abordados na fase de narração central. }\end{array}$ \\
\hline Fala conclusiva & $\begin{array}{l}\text { Buscou-se obter outras informações e questionar o "por } \\
\text { quê" de algumas informações e contradições narradas. } \\
\text { Procedimento realizado a partir de comentários feitos após } \\
\text { o fim da gravação da entrevista e do diário de campo. }\end{array}$ \\
\hline
\end{tabular}

Fonte: Jovchelovitch e Bauer (2002), adaptado pelos autores.

As ENs foram gravadas em áudio e após a transcrição destes documentos pela pesquisadora, foram enviados via e-mail para as participantes da pesquisa, que validaram suas entrevistas. Esse processo de validação da 
entrevista se constituiu na leitura e livre alteração do documento pelas participantes da pesquisa.

\section{Processo de análise das Entrevistas Narrativas}

A análise das ENs inspirou-se nas proposições da Análise de Conteúdo (AC) de Bardin (2006), com o propósito de desvelar os aspectos semânticos no conteúdo das narrativas dos participantes. Consistiu em três momentos: A Pré análise, A Exploração do material e o Tratamento dos resultados obtidos e interpretação, sumariadas no Quadro 2.

Quadro 2 - Momentos da Análise de Conteúdo e descrição do processo

\begin{tabular}{|c|c|}
\hline Momentos da AC & Descrição do processo \\
\hline Pré análise & $\begin{array}{l}\text { Realizou-se a organização e a leitura flutuante das } \\
\text { entrevistas, com o objetivo de constituir impressões } \\
\text { iniciais sobre o que foi narrado. }\end{array}$ \\
\hline Exploração do material & $\begin{array}{l}\text { Refere-se à análise das entrevistas e, a partir do } \\
\text { conteúdo que foi dito pelos entrevistados, construiu-se } \\
\text { os eixos temáticos evidenciados na pesquisa. O } \\
\text { processo de validação dos eixos procedeu por meio de } \\
\text { reuniões com um colaborador externo, que também foi } \\
\text { participante (bolsista de ID) do referido subprojeto, e } \\
\text { fundamentou-se nas proposições apresentadas no artigo } \\
\text { de Henfield, Owens e Witherspoon (2011). }\end{array}$ \\
\hline $\begin{array}{l}\text { Tratamento dos } \\
\text { resultados obtidos e } \\
\text { interpretação }\end{array}$ & $\begin{array}{l}\text { Atribuiu-se sentidos a análise realizada na segunda } \\
\text { fase. Realizou-se as inferências e constituiu-se por fim, } \\
\text { a redação da pesquisa. }\end{array}$ \\
\hline
\end{tabular}

Fonte: Bardin (2006), elaborado pelos autores.

\section{Resultados e Discussão}

Neste artigo, será apresentada a análise do eixo referente à formação do bolsista de ID no contexto da escola Básica referentes as ENs das duas licenciadas (vide Quadro 3). 
Quadro 3 - Período: trajetória de participação dos bolsistas de ID no subprojeto PIBIDQUÍMICA-UFES-ALEGRE no contexto da Escola Básica

\begin{tabular}{|c|c|}
\hline \multicolumn{2}{|c|}{ EIXO TEMÁTICO: FORMAÇÃO DO BOLSISTA DE ID NA ESCOLA BÁSICA } \\
\hline \multicolumn{2}{|c|}{$\begin{array}{l}\text { Descrição: Dizem respeito às ações que as(os) licenciadas(os) desenvolveram como } \\
\text { bolsistas de ID do subprojeto, no contexto das escolas parceiras. Incluem as } \\
\text { atividades formativas do subprojeto ligadas ao contexto escolar, as vivências de } \\
\text { formação que experienciaram no contexto escolar, assim como, suas percepções } \\
\text { sobre essas ações. }\end{array}$} \\
\hline SUBEI & Descrições dos subeixos: \\
\hline $\begin{array}{l}\text { Reconhecimento do } \\
\text { espaço escolar e } \\
\text { acompanhamento } \\
\text { das turmas }\end{array}$ & $\begin{array}{l}\text { Correspondem as atividades de: reconhecimento do contexto } \\
\text { escolar através da inserção das(os) licenciandas(os) } \\
\text { bolsistas de ID nesse espaço de formação, } \\
\text { acompanhamento das aulas do professor supervisor da } \\
\text { escola, observações da dinâmica das aulas e do } \\
\text { comportamento dos alunos, assim como, as percepções dos } \\
\text { bolsistas acerca dessas vivências. }\end{array}$ \\
\hline $\begin{array}{l}\text { Desenvolv } \\
\text { métodos d }\end{array}$ & $\begin{array}{l}\text { Corresponde ao processo de construção de: planejamentos } \\
\text { articulando conteúdos específicos de Química e métodos de } \\
\text { ensino; e desenvolvimento desses planejamentos pelas(os) } \\
\text { licenciadas(os) bolsistas de ID na escola. Abrange também } \\
\text { as percepções das(os) licenciadas(os) bolsistas sobre esse } \\
\text { processo. Essas percepções se referem ao comportamento } \\
\text { do professor supervisor, do aluno e das(os) próprias(os) } \\
\text { bolsistas de ID relacionados a essa vivência formativa no } \\
\text { subprojeto. }\end{array}$ \\
\hline $\begin{array}{l}\text { Relação com alunos } \\
\text { e profissionais da } \\
\text { Educação Básica }\end{array}$ & $\begin{array}{l}\text { Corresponde a relação das(os) bolsistas de ID com os atores } \\
\text { da escola, professores supervisores do PIBID e alunos. Inclui } \\
\text { a forma como essas interações ocorreram e a percepção } \\
\text { das(os) licenciadas(os) sobre essa vivência formativa. }\end{array}$ \\
\hline
\end{tabular}

Fonte: elaborado pelos autores.

\section{Formação inicial docente no subprojeto PIBID-QUÍMICA-UFES-ALEGRE fundamentada nas vivências na Escola Básica}

Em relação à formação inicial no âmbito do subprojeto PIBID, a licenciada Maria conta que além de participarem das reuniões semanais do grupo todo (GT), que aconteciam no âmbito da universidade, os bolsistas de ID também cumpriam horas de formação no contexto das escolas de educação básica, como é afirmado no relato,

[...] É porque o PIBID funcionava assim. [...] A gente tinha as reuniões semanais [do GT] e tinha que ir para a escola. [...] estávamos lá para conhecer a vivência da escola e para testar as coisas [planejamentos] que a gente estudava na pesquisa [...] (MARIA). 
Maria relata que, os bolsistas de ID do subprojeto cumpriam as horas de formação no contexto das escolas de educação básica, conforme préestabelecidas no edital do subprojeto, em que uma das atribuições dos bolsistas indicava a dedicação de no mínimo oito horas semanais às atividades do PIBID, durante o período de vigência da bolsa (PIBID-QUÍMICA, 2013).

Além da possibilidade de conhecimento do cotidiano escolar, a licenciada também entende que essa inserção dos bolsistas no ambiente da escola possibilitava o desenvolvimento dos planejamentos de aula que eram fundamentados por referenciais teóricos.

Nóvoa (2017) afirma que durante o processo de uma formação profissional docente, uma questão importante que deve ser considerada é "como aprender a sentir como professor?". Segundo o autor só é possível aprender a "sentir-se como professor" a partir da inserção do licencianda(o) no ambiente escolar, com a presença de outros professores e com a vivência nessas instituições escolares, pois o eixo articulador de qualquer formação profissional é o contato com a profissão, o conhecimento e a socialização nesse universo profissional.

A partir destes resultados, observou-se a necessidade de se investigar os aspectos vivenciados pelas licenciadas bolsistas de ID, que se relacionam com a inserção das mesmas no ambiente da Escola Básica.

\section{Reconhecimento do espaço escolar e acompanhamento das turmas pelas bolsistas de ID}

As licenciadas contam como foram os momentos de reconhecimento do espaço escolar e de acompanhamento e observação das turmas nas escolas parceiras do subprojeto. Maria narra como aconteceu seu primeiro momento na escola como bolsista de ID do subprojeto e os objetivos de adentrar nesse espaço.

[...] quando entrei no PIBID a gente fez tipo um reconhecimento do ambiente escolar, e, aí nas reuniões [de formação do GT na Universidade] foram dados alguns roteiros, para a gente, que eram meio para guiar nosso olhar na escola: "- Olha! Hoje você vai lá e vai observar tal coisa", "- Hoje você vai chegar lá e 
observar o ambiente", “- Hoje você vai chegar e observar essas coisas direcionadas" (MARIA).

Compreende-se assim que, os primeiros momentos de inserção do bolsista no contexto escolar, oportunizados pelo subprojeto do PIBIDQUÍMICA-UFES-ALEGRE, tinham por finalidade o reconhecimento desse espaço pelo bolsista de ID.

Neste sentido, Maria conta quais desfechos dessa vivência de reconhecimento do espaço escolar, por meio da observação direcionada, a proporcionou.

Fomos conhecendo uma escola que às vezes você estuda tempo, anos lá, e não observa algumas coisas, e esse direcionamento do olhar fez com que a gente conhecesse tanto o ambiente escolar, quanto os alunos, os professores e o pessoal que trabalha lá [...] (MARIA).

Além disso, Maria evidencia que os objetivos desse momento ultrapassam a mera realização de monitorias ou somente a observação da aula ministrada pelo professor supervisor, pois também havia o propósito de investigação dos alunos e do ambiente da sala de aula para que os bolsistas de ID realizassem futuras intervenções do subprojeto.

Então, essas visitas na escola eram isso, geralmente eram direcionadas. Não era só ir para a escola e ficar lá. [...]. Existia um objetivo. Não era só chegar lá e dar monitoria ou ficar assistindo aula. Se você ia para aula você tinha um objetivo de assistir aquela aula e achar alguma coisa ali. [...] era conhecer mesmo o ambiente, as situações e observar coisas que às vezes o professor não observa, o aluno não observa. A gente estava lá para isso e fazia parte da pesquisa [formação docente]. O PIBID [subprojeto de área] era uma pesquisa na área da educação. Não era só dar aula ou aprender a dar aula (MARIA).

Maria compreende que estar na escola com o roteiro de direcionamento proporcionou perceber com um outro olhar o contexto escolar e os atores nele inserido. Neste sentido, Núbia também evidencia sua vivência sobre esse período de inserção no ambiente escolar.

[Estar na escola] Te proporciona ver tanto o lado do aluno como o lado do professor e ao mesmo tempo ter a visão de uma pessoa de fora daquele ambiente, porque de certa forma você está dentro da escola, mas você não faz parte dela, você 
não é professor e nem aluno, então você consegue ver o lado de um, o lado do outro, e o lado dos dois ao mesmo tempo, e isso te faz refletir bastante (NÚBIA).

Compreende-se que esta vivência possibilita aos bolsistas reorientarem suas percepções sobre o ambiente e atores da escola, mas na posição de um docente em formação inicial.

Silva e Aragão (2012) afirmam que a observação de um ambiente permite a apreensão da realidade, isto é, apreender significa aprender através do intelecto humano. Assim, todo o conhecimento de um objeto ou um fato é considerado como ação do sujeito que realizou o processo de observação. Para os autores "[...] a aprendizagem pode ser compreendida como sendo o resultado de processos interativos entre os indivíduos e das observações que realizam sobre o meio, os elementos, os fatos e os acontecimentos [...]" (p. 53).

O reconhecimento do espaço escolar é uma atividade relevante em um processo formativo docente, uma vez que, por meio da observação desse ambiente o sujeito em formação tem a possibilidade de conhecer e analisar de maneira mais criteriosa os fatores que fazem parte e interferem no seu futuro ambiente de atuação profissional.

Outra característica observada pela análise das entrevistas refere-se às percepções de Núbia acerca de algumas observações realizadas durante as aulas de Química das escolas que acompanhou como bolsistas do subprojeto.

Outra coisa que chamava atenção é que sempre que ia na sala de aula e observava uma aula de 50 minutos uns 10 a 20 minutos era sempre para acalmar a turma, outros 10 para fazer chamada, e no final das contas chegava alguém da secretaria para dar algum recado e na hora que o professor chegava para ministrar aula, de fato, eram 10 ou 5 minutos no final para terminar a aula. Isso me incomodava bastante [além da] [...] falta de interesse e de respeito por parte dos alunos (NÚBIA).

Percebe-se que a dinâmica escolar, mencionada pela licenciada, Ihe causou estranhamento, isto por que ela estava inserida em outra dinâmica, a da Universidade, em um processo de formação profissional, que possui regras e valores distintos da Educação Básica. Este estranhamento pode ser um indício de que a licenciada construiu uma profissionalidade docente, 
evidenciado pela frustração frente aos dilemas que o professor vivenciou na sala de aula.

Em relação a falta de interesse dos alunos durante as aulas, Núbia conta que os comportamentos deles eram diversos: alguns não permaneciam dentro da sala de aula, outros conversavam durante o desenvolvimento da atividade, outros não respondiam as perguntas que eram realizadas por ela ou pelo professor/supervisor.

O descaso dos alunos com o ambiente escolar pode ter vários fatores, a forma como os conteúdos educacionais são abordados nos programas escolares durante as aulas de Química é um exemplo apontado por Paz e Pacheco (2010),

Em geral, nos programas escolares verifica-se uma quantidade enorme de conteúdos a serem desenvolvidos, com minuciosidades desnecessárias, de modo que os professores se veem obrigados a correr com a matéria, amontoando um item após outro na cabeça do aluno. Percebe-se um currículo de química divergente das propostas defendidas pela comunidade de pesquisadores em Educação Química, que consideram nos processos de construção do conhecimento escolar a inter-relação dinâmica de conceitos cotidianos e químicos, de saberes teóricos e práticos, não na perspectiva da conversão de um no outro, nem da substituição de um pelo outro, mas, sim pelo diálogo capaz de ajudar no estabelecimento de relações entre conhecimentos diversificados, pela constituição de um conhecimento plural capaz de potencializar a melhoria da vida (PAZ; PACHECO, 2010, p. 2)

Neste sentido, Núbia relata que, o comportamento dos alunos modificava mesmo que de forma moderada, quando outras atividades "diferenciadas" eram desenvolvidas. Um exemplo eram as atividades experimentais, realizadas em sala de aula ou no laboratório.

Portanto, compreende-se que ao narrar essa vivência da Escola Básica, Núbia reflete sobre a prática docente de Química no contexto escolar e consequentemente sobre sua futura prática docente, pois compreende que trabalhar com essas atividades com os alunos propiciava a eles certa motivação e evitava a rotina das aulas por alguns momentos.

Neste sentido, a relação narrativa e formação se entrelaçam no momento em que o sujeito organiza suas ideias para o relato oral ou escrito, 
pois reconstrói sua experiência formativa de forma reflexiva, realizando uma (auto)análise do que foi experienciado, concebendo novos fundamentos para a compreensão de sua própria experiência (CUNHA, 1997).

Núbia também percebeu as interrupções das aulas por outros atores da escola e a falta de interesse dos alunos. Essas foram as situações observadas e evidenciadas pelas licenciadas que, segundo elas, interferiam diretamente no andamento das aulas que acompanharam na escola, vivência oportunizada pela sua participação no subprojeto.

\section{Desenvolvimento de métodos de ensino com os alunos da escola parceira}

Ainda, sobre a inserção das bolsistas de ID no contexto escolar, Maria relata que os atores da escola entendiam a presença deles como uma assistência às demandas do Ensino de Química da escola, a partir do desenvolvimento de atividades de monitorias pelos bolsistas do subprojeto com os alunos.

[...] a escola não era [só] assistir aula e também não era monitoria. E isso na época, eu lembro que, quando o professor colaborador A chegou com essa proposta [diferente], o pessoal das escolas daqui da região não adaptou muito, não gostaram muito, porque eles estavam esperando que a gente fosse dar monitoria e ensinar Química para a galera [os alunos]. Só que na verdade estávamos lá para conhecer a vivência da escola e para testar as coisas [planejamentos] que a gente estudava na pesquisa [...] (MARIA).

Todavia, como é expresso no relato de Maria, em oposição a essa proposta de oferecimento frequente de monitorias de Química nas escolas, os professores coordenadores e colaboradores responsáveis pelo subprojeto, tinham como objetivo o desenvolvimento de uma formação docente com foco no processo formativo dos licenciandos oportunizando, por exemplo, atividades que articulavam o conteúdo específico de Química com as metodologias de ensino, formação esta que é escassa na maioria dos cursos de formação de professores de Química.

Neste sentido, é que no relato de Maria há reflexão sobre a inserção do bolsista ID no contexto escolar, como possibilidade de "testar a pesquisa" que 
estavam desenvolvendo com o grupo GT. O termo pesquisa refere-se ao estudo de artigos que embasaram teórico-metodologicamente a construção dos planejamentos das intervenções pelos bolsistas, norteando-os no desenvolvimento de atividades que articulavam os conteúdos de Química as metodologias de ensino. Assim, antes de desenvolverem as intervenções nas escolas parceiras, o planejamento da atividade era apresentado nas reuniões de GT na Universidade, momento em que ocorria a avaliação desses planejamentos pelos integrantes do subprojeto.

Dentre as intervenções realizadas pelos bolsistas de ID do subprojeto, as licenciadas fazem referência ao estudo e desenvolvimento do método de ensino por Resolução de problemas com os alunos das escolas básicas.

Uma experiência que me marcou foi o estudo de Resolução de Problemas. Foi a última experiência que eu tive na escola, ficou marcada [...]. Eu acredito que é pelo fato de ser parecido com o que a gente vive no dia a dia. Porque se for parar para pensar nós estudamos para quê? Na minha concepção é para ter uma base, para se tornar um cidadão capaz de formar opinião e resolver coisas. Porém, o que vemos hoje em dia são pessoas incapazes de opinar sobre algo, gente que não pensa, apenas reproduz e procura respostas prontas. Esse método provoca a curiosidade, te faz questionar e querer resolver [problemas] (NÚBIA).

[...] teve um [método] que marcou muito que foi um que tinha motivação. Eu sei que tinha a etapa de motivar o aluno, e tinha a aula específica e a reflexão sobre a aula [...] (MARIA).

Embora Maria tenha citado as etapas do método de ensino por Resolução de problemas, durante toda entrevista ela não se recorda do nome do referido método. Núbia ressalta que em sua percepção o método tem uma finalidade prática e, por isso, o entende como um potencial instrumento para formar cidadãos que pensem e questionem sobre problemas da vida cotidiana utilizando o conhecimento científico de Química. É notório, portanto, que para as licenciadas essa vivência de desenvolvimento do método ficou marcada em sua formação inicial.

Além disso, as licenciadas revelam suas percepções sobre 0 desenvolvimento de métodos de ensino com os alunos na escola. 
[...] e a gente tinha essa vivência e oportunidade de estudar os métodos e testar lá com os alunos. [...] tanto eles se interessavam, pois era uma coisa diferente do que eles estavam acostumados na sala de aula, e era uma coisa diferente para nós também, porque estávamos testando uma prática na vivência da escola (MARIA).

[Desenvolver o método de Resolução de problemas] foi interessante. Não atendia todos da sala porque tem aluno que se identifica mais com um experimento ou resolvendo questões no caderno. São pessoas diferentes que aprendem de modos diferentes [...] às vezes chama atenção de um, mas não chama a atenção do outro [aluno] (NÚBIA).

É possível analisar que, para Maria, um aspecto eminente a essa atividade do subprojeto, concerne a possibilidade de incentivar o interesse dos sujeitos envolvidos no processo por promover aos alunos outras experiências que envolvam os conteúdos de Química, que sejam diferentes das aulas corriqueiras e, por outro lado, aos bolsistas a experiência de estudar e desenvolver um método de ensino com os alunos no espaço escolar.

Por outro lado, embora Núbia compreenda a potencialidade e importância do método por Resolução de problemas, um aspecto identificado e evidenciado pela licenciada concerne às limitações do método, uma vez que, não foi possível estimular o interesse de todos os alunos da turma, percebendo que cada aluno possui especificidades diferentes em relação ao processo de ensino e aprendizagem de Química. Este resultado é outro indício de que o planejamento e desenvolvimento das atividades orientadas no subprojeto PIBID-QUÍMICA-UFES-ALEGRE possibilita reflexões sobre a atividade profissional docente no contexto escolar.

Desta forma, uma problemática decorrente da estrutura curricular dos cursos de formação de professores possui vários níveis de desarticulação, dentre eles: "[...] i) entre as disciplinas específicas e pedagógicas; ii) entre as disciplinas de conteúdo específico como um todo e destas com o ensino de Química; iii) entre as disciplinas pedagógicas como um todo e destas com o ensino de Química [...] (SCHNETZLER, 2000, p. 22). Segundo Zeichner (2010) a falta de conexão entre a formação nas Universidades e o campo da prática é considerado um grande problema na formação para a docência. 0 distanciamento existente entre espaços de formação e de trabalho devem 
constituir fator de grande preocupação entre os responsáveis pela formação dos professores.

Os resultados evidenciam que participar do subprojeto PIBID-QUÍMICAUFES-ALEGRE possibilita a formação do bolsista de ID no viés da articulação entre teoria-prática e escola-Universidade, essencial para desenvolver um repertório de práticas de ensino de Química que os auxiliem em sua futura atuação docente na Educação Básica.

Sobre as dificuldades enfrentadas pelos professores em sua atuação, Maria compreendendo que estas dificultam o desenvolvimento de tais métodos de ensino pelos professores, sendo levados a desenvolverem o ensino de Química de forma mecânica.

[...] Uma oportunidade que, às vezes, os professores não têm tanto, pela agenda lotada de muito conteúdo para passar na sala. E literalmente, a palavra é passar. Infelizmente! E acabam não tendo esse espaço que pode acrescentar muito (MARIA).

Essa problemática persistente no exercício da profissão docente, que diz respeito a demanda de conteúdos específicos da proposta curricular para a disciplina de Química para o Ensino Médio, que os professores necessitam ministrar, que resulta na falta de espaço para o professor planejar e desenvolver atividades distintas que estimulem nos alunos maior interesse pelos conteúdos de Química (PAZ; PACHECO, 2010).

Percebe-se na narrativa de Maria uma preocupação para além da formação profissional nos cursos de formação de docentes, para que o docente possa trabalhar com novas propostas metodológicas para o ensino de Química é necessário também condições de trabalho para o professor.

Nesta perspectiva Bego et al. (2014) investigaram as condicionantes relacionadas à utilização de atividades experimentais, que interferem na atuação dos professores da Educação Básica. Para tanto, foram realizadas entrevistas na perspectiva de grupo focal, com seis professoras da Educação Básica. Os resultados da análise das entrevistas mostram que são quatro os principais condicionantes: i) organização da escola e das aulas, principalmente pelo elevado número de alunos por turma; ii) condições estruturais e materiais, por exemplo, falta de um local adequado, de material e equipamentos; iii) 
relacionados ao professor, insegurança ou falta de tempo para o planejamento de tais atividades; e iv) comportamento do aluno, relacionado à indisciplina.

Outras dificuldades vivenciadas por Maria, se relacionam ao entendimento dos fundamentos teórico-metodológicos do método de ensino, ao planejamento e desenvolvimento do mesmo com os alunos na escola em que atuou como bolsistas de ID do subprojeto.

[...] É o fato [do método ser] diferente, de ser diferente do que as coisas que as pessoas estão acostumadas [...]. [...] [No PIBID tinha que] sentar e estudar um método e ir a fundo nele, tanto em relação a estudar como utilizá-lo, quanto de onde ele veio, quem são os pensadores, quem são os professores por trás desse método. Esse tipo de coisa que o professor não pensa quando está planejando uma aula e nós pensávamos em tudo. Tanto em estudar quanto planejar possíveis pensamentos que os alunos podem ter expostos a tal situação. [...] [a dificuldade também, se relaciona a] falta de equipamentos no laboratório. Lá em Celina não tinha um laboratório [específico para a disciplina de Química]. [...]. Então às vezes você vai testar algumas coisas com os alunos, tinha que ser na sala de aula mesmo. Por exemplo, [...] quando a gente fez o teste de chama na sala de aula. [...] (Maria).

Segundo Maria, trabalhar com uma metodologia de ensino diferente (articulada ao conteúdo específico) era difícil por se tratar de uma proposta diferente do que estava acostumada a partir de suas vivências como estudante da Escola Básica e de licenciatura. Neste sentido, um ponto importante a se destacar é a importância atribuída, pelos coordenadores e colaboradores do subprojeto, ao estudo do método, construção e desenvolvimento dos planejamentos de aula pelos bolsistas de ID.

Assim, além das dificuldades inerentes ao método de ensino, estas se acentuavam devido as problemáticas da escola, por exemplo, a falta de infraestrutura apropriada para realizar aulas práticas de Química, como conta Maria, sendo essas realizadas em lugares inapropriados como a sala de aula. No âmbito nacional, esse problema é uma preocupação recorrentemente citada na literatura especializada (GONÇALVES, MARQUES, 2012; MATIELLO, 2017). Essas pesquisas visam identificar e minimizar os problemas e propor alternativas para o desenvolvimento de atividades experimentais alternativas de baixo custo e fácil acesso. 
Portanto, André (2012, p. 115) ressalta que o professor tem um papel relevante no sucesso da aprendizagem, todavia, existem outros fatores que igualmente devem ser considerados para que se obtenha uma educação de qualidade, tais como "[...] recursos disponíveis nas escolas; uma organização do trabalho escolar que propicie suporte físico, pedagógico e emocional aos docentes; salários dignos, condições de trabalho adequadas e carreira atrativa". Segundo a autora, deve-se levar em consideração esse conjunto de condições para que se possa elaborar políticas públicas que possibilitem melhores condições ao trabalho docente e, portanto, a elevação da qualidade da Educação Básica.

\section{Relação com alunos e profissionais da Educação Básica}

As licenciadas relataram a forma como ocorreram as interações com os atores da Escola Básica. Maria conta que no geral mantinha uma boa relação com a diretora e com os professores/supervisores do subprojeto, que atuavam na escola parceira ao subprojeto PIBID-QUÍMICA-UFES-ALEGRE, ressaltando que, inclusive, obteve relação cordial com uma professora/supervisora do subprojeto que atuava na referida escola. E mesmo aqueles que a licenciada não teve grande interação, a parceria estabelecida contribuiu para desenvolver as atividades no contexto escolar.

De outro modo, Núbia relata que, com os alunos ela mantinha uma boa relação e aproveitava os momentos em que o professor/supervisor passava exercícios durante as aulas e os intervalos de recreação para se aproximar e conhecê-los. Quanto a relação com os professores/supervisores, a licenciada conta algumas situações complexas vivenciadas no contexto escolar que influenciavam desfavoravelmente em sua interação com os mesmos.

[...] Eu sentia que a gente incomodava eles [os professores/supervisores]. [...] Quando a gente planejava algo diferente e os alunos mostravam algum tipo de interesse, você via que isso incomodava eles. Não sei se era medo de algum momento a gente tomar o lugar deles, ou se medo dos alunos ficarem cobrando para que eles fizessem a mesma coisa. Eu tinha a sensação que eles se sentiam incomodados da gente estar lá fazendo algo diferente (NÚBIA). 
[...] Nunca ninguém chegou para mim e falou: "- Não vai assistir minha aula, não gosto de você aqui". [...] mas tudo que a gente propunha sentia um pouco de resistência por parte deles. De uns cinco professores que eu já trabalhei, um mostrava interesse: "- A gente pode fazer isso mesmo, acho que isso vai chamar a atenção". Que eu me lembre um que se mostrava aberto a propostas, aberto a fazer algo diferente. Os outros sempre diziam: "- Deixa assim mesmo não dá para fazer", "- Ah você não vai conseguir fazer isso porque os alunos são muito difíceis, vão ficar gritando, não vai dar para fazer isso não". Parecia que não queriam nem tentar. Eu não sei se é porque eles já estavam muito desmotivados ou se sentiam ameaçados por ter outra pessoa lá que queria fazer algo [diferente do que eles faziam] (NÚBIA).

Núbia relata que, em sua percepção, havia incômodo por parte da maioria dos professores/supervisores quanto à sua presença no ambiente escolar, em sua percepção os professores se sentiam pressionados com a presença dos bolsistas de ID na escola. Esse incômodo refletia, por exemplo, nos momentos em que eles apresentavam algumas sugestões de atividades para serem realizadas com os alunos durante as aulas, pois, segundo ela, os professores se mantinham resistentes a novas propostas.

Desta forma, Maria manteve boa relação com o corpo técnico e alunos das escolas em que atuou como bolsista de ID, por outro lado Núbia não relatou o estabelecimento de relações de parceria com a maioria dos professores supervisores das escolas em que atuou como bolsista de ID do subprojeto, mas sim com os alunos.

No que se refere a essa vivência evidenciada no relato das licenciadas, compreende-se que o estabelecimento de uma boa relação entre professor e aluno é uma condição importante no processo de ensino e aprendizagem, o que deve ser levado em consideração durante um processo de formação inicial docente, pois dependendo de como ocorre a interação entre ambos, a aprendizagem do aluno pode ser facilitada em diferentes níveis, pois é essa interação que conduz o processo educativo (SANTOS, 2001).

Desta forma, embora não tenham sido evidenciadas nas narrativas das licenciadas, atividades denominadas de "Quebra-gelo" foram adotadas no processo formativo do PIBID-QUÍMICA-UFES-ALEGRE com o objetivo de aproximar os bolsistas de ID dos atores da escola. Os bolsistas eram 
orientados, pelos professores coordenadores e colaboradores do referido subprojeto, a planejarem essas atividades com os professores/supervisores e depois as desenvolverem durante a vivência de reconhecimento do ambiente escolar. Este posicionamento colabora para a compreensão de que havia preocupação, por parte dos professores formadores do subprojeto, de que os bolsistas de ID estabelecessem boas relações com atores da escola para facilitar, a inserção dos bolsistas de ID no ambiente da Escola.

No que diz respeito a relação entre o professor da escola e licenciando, é importante enfatizar que haja uma relação de parceria durante o processo de inserção do licenciando no ambiente escolar, na perspectiva de que durante seu processo de formação inicial possa constituir saberes de experiência produzidos pelos professores da escola no cotidiano docente (PIMENTA, 1999). Por outro lado, é fundamental que o professor da escola colabore na adoção de novas propostas de ensino, com o objetivo de reconstruírem suas práticas docente para a melhoria do ensino.

Portanto, em relação a formação do bolsista no contexto da Escola Básica, analisou-se aspectos relacionados às vivências formativas de: a) reconhecimento do espaço escolar e acompanhamento das turmas; b) desenvolvimento de métodos de ensino com os alunos e c) relação com os alunos e profissionais das escolas parceiras.

\section{Considerações}

A partir dos aspectos atrelados às vivências no subprojeto, as licenciadas evidenciaram aspectos que consideraram mais relevantes para a sua formação inicial no contexto escolar, atribuindo significados ao que foi vivenciado. Portanto, a investigação das Histórias de vida em formação, por meio das narrativas das licenciadas, possibilitou compreender parte do processo de formação inicial do subprojeto PIBID-QUÍMICA-UFES-ALEGRE, no contexto da Escola Básica. As vivências narradas fomentaram reflexões nas licenciadas sobre diversos aspectos, entre eles: i) o reconhecimento do contexto escolar; ii) a percepção do comportamento dos alunos e dos impasses enfrentados pelos professores/supervisores no desenvolvimento das aulas; iii) 
a observação e discussão direcionada da infraestrutura das escolas parceiras, mais especificamente, ao ambiente laboratorial; iv) o estabelecimento de relações com alunos e profissionais da Escola Básica; e v) a percepção do comportamento dos professores/supervisores e alunos frente a propostas de atividades diferenciadas, por exemplo, a utilização da metodologia de Resolução de Problemas.

Nesse sentido, os resultados da investigação indicam que, participar como bolsista de ID do subprojeto PIBID-QUÍMICA-UFES-ALEGRE, contribuiu para a formação inicial docente das licenciadas. Esta formação se deu pela vivência no contexto da Escola Básica, balizada pela constante discussão e reflexão nos encontros semanais do subprojeto PIBID.

Esses anos de expansão e estabelecimento do PIBID em âmbito nacional, demonstra que esse programa de formação viabiliza um caminho, no sentido de valorizar o magistério, pelo fomento a projetos de ensino, que demonstram igualmente a importância da articulação entre as áreas de conhecimento pedagógico e específico da Química, a formação na prática e reflexões acerca do que se vivencia durante esse processo de formação inicial. O PIBID, diz respeito à efetivação de uma proposta que fomenta uma política pública para a área de Educação, que valoriza os profissionais que nela estão inseridos e os sujeitos que estão ingressando nas licenciaturas possibilitando mudanças nas posturas e concepções dos participantes.

\section{Agradecimentos}

O presente trabalho foi realizado com apoio: da Coordenação de Aperfeiçoamento de Pessoal de Nível Superior - Brasil (CAPES). Código de financiamento 001, e, do Programa de Pós-graduação em Ensino, Educação Básica e Formação de Professores da Universidade Federal do Espírito Santo (PPGEEDUC-UFES). 


\section{Referências}

ANDRÉ, M. Políticas e Programas de apoio aos professores iniciantes no Brasil. Rev. Cadernos de pesquisa, São Paulo, v.42, n.145 p.112-129, jan./abr., 2012.

BARDIN, L. Análise de conteúdo. 3. ed. Lisboa: Ed. 70, 2006. 223 p.

BEGO, A. M.; SALVADOR, G.; GERMANO, A. M.; GOMES, N. E.; CENTURION, E. H. B.; IBRAHIM, J. Condicionantes sobre o trabalho docente: A utilização de atividades experimentais em uma rede escolar pública municipal. Rev. Química nova escola, São Paulo - SP, BR, vol. 36, n. 3, p. 176-184, ago., 2014.

BRASIL. Lei N$^{\circ} \mathbf{9 . 3 9 4}$ de 20 de dezembro de 1996. Estabelece as diretrizes e bases da educação nacional. Disponível em: http://portal.mec.gov.br/seesp/arquivos/pdf/lei9394_Idbn1.pdf. Acesso em: 08 out. 2020.

BRASIL. Portaria Normativa $n^{\circ}$ 38, de 12 de dezembro de 2007. Dispõe sobre o Programa de Bolsa Institucional de Iniciação à Docência - PIBID. Disponível em: http://portal.mec.gov.br/arquivos/pdf/portaria_pibid.pdf. Acesso em: 25 jun. 2020.

CAPES-DEB. Diretoria de Formação de Professores da Educação Básica DEB Relatório de gestão DEB 2009-2014. Brasília, 2014. 119 p.

CUNHA, M. I. Conta-me agora! As narrativas como alternativas pedagógicas na pesquisa e no ensino. Rev. Faculdade de Educação, São Paulo, v. 23, n.1/2, p. 185-195, jan./dez., 1997.

ECHEVERRÍA, A. R.; BENITE, A. M. C.; SOARES, M. H. F. B. A pesquisa na formação inicial de professores de química: a experiência do Instituto de Química da Universidade Federal de Goiás. In: REUNIÃO ANUAL DA SOCIEDADE BRASILEIRA DE QUÍMICA, 30., 2007, Águas de Lindóia. Anais... Águas de Lindóia: SBQ, $2007 . \quad$ Disponível em: http://www.sbq.org.br/30ra/wordensino.php. Acesso em: 08 out. 2020.

GATTI, B. A. Formação de Professores no Brasil: características e problemas. Rev. Educação e Sociedade, Campinas, v. 31, n. 113, p. 1355-1379, out./dez., 2010.

GATTI, B. A.; ANDRÉ, M. E. D. A.; GIMENES, N. A. S.; FERRAGUT, L. Um estudo avaliativo do Programa Institucional de Bolsas de Iniciação à Docência (PIBID). Fundação Carlos Chagas, São Paulo: FCC/SEP, 2014.

GATTI, B. A.; BARRETO, E. S. de S. Professores do Brasil: impasses e desafios. Brasília: UNESCO, 2009. 294 p.

GONÇALVES, F. P.; MARQUES, C. A. Circulação inter e intracoletiva de pesquisas e publicações acerca da experimentação no ensino de Química. 
Rev. Brasileira de Pesquisa em Educação em Ciências, Belo Horizonte, v. 12, n. 1, p. 181-204, 2012.

HENFIELD, M. S.; OWENS, D.; WITHERSPOON, S. African American students in counselor education programs: Perceptions of their experiences. Counselor Education and Supervision, v. 50, p. 226-242, jun., 2011.

JOSSO, M. C. A transformação de si a partir da narração de histórias de vida. Rev. Educação, Porto Alegre/RS, n. 3 (63), p. 413-438, set./dez., 2007.

JOVCHELOVITCH, S.; BAUER, M. W. Entrevista Narrativa. In: GASKELL, G.; BAUER, M. W. Pesquisa qualitativa com texto, imagem e som: um manual prático. $4^{\mathrm{a}}$ ed. Petrópolis, RJ: Vozes, 2002. p. 90-113.

LÜDKE, M.; ANDRÉ, M. E. D. A. Pesquisa em educação: abordagens qualitativas. São Paulo: EPU, 2014.

MATIELLO, J. R. Uma análise das teses e dissertações sobre experimentação no ensino de Química no Brasil: 2000 a 2012. 2017. 66 f. Dissertação (Mestrado em Ensino de Química) - Ensino de Ciências (Física, Química e Biologia), Universidade de São Paulo, São Paulo, 2017.

MINAYO, C. S.; DESLANDES, S. F.; GOMES, R. Pesquisa social: teoria, método e criatividade. 28. ed. Petrópolis, RJ: Vozes, 2009. 109 p.

NÓVOA, A. Firmar a posição como professor, afirmar a profissão docente. Rev. Cadernos de Pesquisa, São Paulo, v. 47, n. 166, p. 1106-1133, out./dez., 2017.

PAZ, G. L.; PACHECO, H. F. Dificuldades no ensino-aprendizagem de Química no ensino médio em algumas escolas públicas da região sudeste de Teresina. In: X Simpósio de Produção Científica e IX Seminário de Iniciação Científica, 2010. p. 1 - 14. Resumos... Piauí: Universidade Estadual do Piauí, 2010. Disponível:https://www.uespi.br/prop/siteantigo/XSIMPOSIO/TRABALHOS/INIC IACAO/Ciencias\%20da\%20Natureza/DIFICULDADES\%20NO\%20ENSINOAPR ENDIZAGEM\%20DE\%20QUIMICA\%20NO\%20ENSINO\%20MEDIO\%20EM\%2 OALGUMAS\%20ESCOLAS\%20PUBLICAS\%20DA\%20REGIAO\%20SUDESTE \%20DE\%20TERESINA.pdf. Acesso em: 08 out. 2020.

PEREIRA, T. M., RECEPUTI, C. C.; REZENDE, D. B. Potencialidade do PIBID para além da formação de seus bolsistas: relatos de uma coordenadora. Rev. História Oral, v. 23, n. 1, p. 77-91, jan./jun., 2020.

PIBID-QUÍMICA. Programa Institucional de Bolsa de Iniciação à Docência PIBID. EDITAL NN 61/2013 - CAPES/DEB. Detalhamento de SUBPROJETO (Licenciatura). 2013, p. 1-12.

PIMENTA, S. G. Formação de Professores: identidade e saberes da docência. In: PIMENTA, S. G. Saberes pedagógicos e atividade docente. 2. ed. São Paulo: Cortez. 1999. p. 15-34. 
SANTOS, S. C. dos. O processo de ensino-aprendizagem e a relação professor-aluno: aplicação dos "sete princípios para a boa prática na educação superior". Rev. Cadernos de pesquisa em administração, São Paulo, v. 08, n. 1, jan./mar, 2001.

SCHEIBE, L. Formação de professores no Brasil A herança histórica. Rev. Retratos da Escola, Brasília, v. 2, n. 2-3, p. 41-53, jan./dez., 2008.

SCHNETZLER, R. P. O professor de Ciências: problemas e tendências de sua formação. In: SCHNETZLER, R. P.; ARAGÃO, R. M. R. de. (Orgs.). Ensino de Ciências: fundamentos e abordagens. Piracicaba: CAPES/PROIN/UNIMEP, 2000, p. $12-41$.

SILVA, C. S. da; OLIVEIRA, L. A. A. de Formação inicial de professores de química: formação específica e pedagógica. In: NARDI, R. org. Ensino de ciências e matemática I: temas sobre a formação de professores [online]. São Paulo: Editora UNESP; São Paulo: Cultura Acadêmica, 2009. p. 42-57. Disponível em: http://books.scielo.org/id/g5q2h/pdf/nardi-978857983004404.pdf. Acesso em: 09 mar. 2020.

SILVA, F. L. Coordenadores de área do PIBID: um olhar sobre o desenvolvimento profissional. 2015. 154f. Dissertação (Mestrado em Ensino de Química) - Ensino de Ciências (Física, Química e Biologia), Universidade de São Paulo, São Paulo. 2015.

SILVA, N. M. DA; ARAGÃO, R. F. A observação como prática pedagógica no ensino de geografia. Rev. Geosaberes, Fortaleza, v. 3, n. 6, p. 50-59, jul. /dez., 2012.

SILVA, R. M. G. da; SCHNETZLER, R. P. Constituição de professores universitários de disciplinas sobre ensino de Química. Rev. Química Nova, Vol. 28, n. 6, p. 1123-1133, nov., 2005.

VOGEL, M. Influências do PIBID na representação social de licenciandos em química sobre ser "professor de química". 2016. 220 f. Tese (Doutorado em Ensino de Química) - Ensino de Ciências (Física, Química e Biologia), Universidade de São Paulo, São Paulo. 2016.

VOGEL, M. V.; SCARAMUSSA, D. S.; MACHADO, H. S.; PEREIRA, T. M.; VOGEL, A. J. Z. Avaliação da construção de oficinas temáticas na perspectiva dos bolsistas PIBID-QUÍMICA: Potencialidades e dificuldades. Rev. de Educação, Ciências e Matemática, v. 8, n. 3, set./dez., 2018.

ZEICHNER, K. Repensando as conexões entre a formação na Universidade e as experiências de campo na formação de professores em faculdades e Universidades. Rev. Educação, Santa Maria - RS, v. 35, n. 3, p. 479-504, 2010. 


\section{Sobre os autores}

\section{Hedylady Santiago Machado}

hedyladysantiago@gmail.com

Mestranda no Programa de Pós-Graduação em Ensino, Educação Básica e formação de Professores (PPGEEDUC) da Universidade Federal do Espírito Santo (UFES). Licenciada em Química pela Universidade Federal do Espírito Santo (UFES). Participante do Grupo de Estudo Étnico-Racial e Educação (GEERE-UFES).

\section{Caian Cremasco Receputi}

caian.receputi@gmail.com

Mestre em Ensino de Ciências pela Universidade de São Paulo (USP). Doutorando no Programa de Pós-Graduação Interunidades em Ensino de Ciências (PIEC) da USP. Participante do Grupo de Pesquisa Linguagem no Ensino de Química (LiEQui).

\section{Marcos Vogel}

mrvoge12006@gmail.com

Doutor em Ensino de Ciências pela Universidade de São Paulo (USP). Coordenador Institucional do Programa Institucional de Bolsa de Iniciação à Docência (PIBD) da Universidade Federal do Espírito Santo (UFES). Professor Adjunto da Universidade Federal do Espírito Santo (UFES). Pesquisador do Grupo de Pesquisa Linguagem no Ensino de Química/LIEQUI/USP/CNPq. 